\title{
Aplikasi Sistem Informasi Pemendek URL (SI SOUP) Berbasis Web
}

\author{
Sutrisno', Aprih Widayanto², Muhammad Robi Syahiri ${ }^{3}$ \\ 1.3Universitas Bina Sarana Informatika, STMIK Nusa Mandiri² \\ 1sutrisno.stz@bsi.ac.id, 2aprih.apz@nusamandiri.ac.id, 3robisyahiri@gmail.com
}

\begin{abstract}
URL shortener is a technique on the WWW that makes a web page accessible by using a very short URL in addition to the original address. Internet users use this URL shortening application service when finding a very long URL, and users find it difficult to remember the URL address, so that requires an application that can shorten the URL, so that the URL address becomes easier to remember for himself and for others. This research will focus on building a URL shortener application with two services, namely shortened URL shortener, and special shortened URL shortener. URL shortener results are random, i.e. URL shortener results are randomized by the system, and users cannot determine their own results from the URL shortener. The special result URL shortener is the URL shortening result that is determined by the user, and the user can determine the URL shortening result by inputting the results as desired in the system, and this user will successfully input them, if the URL results have not been used by other users.
\end{abstract}

Keywords: URL shortener, randomly generated URL shortener, custom result URL shortener

Abstrak: Pemendek URL adalah suatu teknik pada WWW yang membuat suatu halaman situs dapat diakses dengan menggunakan suatu URL yang sangat pendek selain alamat aslinya. Pengguna internet menggunakan layanan aplikasi pemendek $U R L$ ini bila menemukan $U R L$ yang sangat panjang, dan pengguna merasa kesulitan untuk mengingat alamat $U R L$ tersebut, sehingga memerlukan aplikasi yang bisa memperpendek $U R L$, sehingga alamat $U R L$ menjadi lebih mudah untuk diingat bagi dirinya dan bagi orang lain. Pada penelitian ini akan berfokus untuk membangun aplikasi pemendek URL dengan dua layanan, yaitu pemendek $U R L$ hasil acak, dan pemendek URL hasil khusus. Pemendek URL hasil acak, yaitu hasil pemendek URL diacak oleh sistem, dan pengguna tidak bisa menentukan sendiri hasil dari pemendek URLnya. Pemendek URL hasil khusus yaitu hasil pemendek URL ditentukan oleh pengguna, dan pengguna bisa menentukan hasil pemendek URLnya dengan cara menginputkan hasil sesuai keinginan di sistem, dan pengguna ini akan berhasil menginputkannya, bila hasil $U R L$ tersebut belum digunakan oleh pengguna lain.

Kata kunci: Aplikasi Pemendek URL, Pemendek URL hasil acak, Pemendek URL hasil khusus

This is an open access article distributed under the Creative Commons Attribution License, which permits unrestricted use, distribution, and reproduction in any medium, provided the original work is properly cited. O2019 by author and IJSE-Indonesian Journal on Software Engineering.

\section{A. PENDAhUluAN}

Pengguna internet di berdasarkan laporan terbaru situs We Are Social, pada tahun 2020 mencapati 175,4 juta pengguna internet di Indonesia. Pengguna internet, khususnya yang menggunakan komputer dekstop / laptop, tentu saja akan memanfaatkan browser untuk mendapatkan informasi ketika mereka berselancar di dunia maya tersebut.

Pada saat berselancar di internet dan menemukan informasi yang menarik, kadang mereka ingin berbagi kepada pengguna internet yang lainnya. Nah untuk membaginya tersebut, mereka akan menyalin alamat url dari berita/informasi yang mereka dapatkan. Biasanya url yang akan dibagikan itu panjang, sehingga sulit untuk diingat. Oleh karenanya, untuk mempermudahnya, mereka perlu memperpendek url tersebut, dengan pemendek url. 
Oleh karena itu, dalam penelitian ini akan membuat Aplikasi pemendek URL untuk memenuhi kebutuhan pengguna internet agar ketika akan membagikan URL lebih mudah karena $U R L$ jadi mudah diingat karena lebih pendek, dan aplikasi ini dianmakan Si SOUP, kependekan dari Sistem Informasi Pemendek URL.

SI SOUP dibagun dengan 2 (dua) jenis URL, yang pertama URL hasil acak, yang kedua URL hasil khusus. URL hasil acak maksudnya, hasil dari $U R L$ tersebut diacak oleh sistem, dan pengguna tidak bisa menentukan sendiri hasil dari URLnya. Sedangkan URL hasil khusus adalah hasil dari URL tersebut sesuai dengan keinginan dari pengguna, dan pengguna bisa menginputkan langsung ke dalam sistem SI SOUP, bila hasil URL tersebut belum ada di database, atau belum diinput oleh dirinya dan pengguna lainnya. Bila hasil URL tersebut sudah ada diinput oleh pengguna lain, maka pengguna bisa mengganti

\section{B. TINJAUAN PUSTAKA \\ 1. Konsep Dasar Web}

Satu layanan yang didapat oleh pemakai komputer yang terhubung ke internet. Web dapat diartikan sebagai kumpulan halaman-halaman yang digunakan untuk menampilkan sebuah artikel, gambar diam atau gerak, animasi, suara dan atau gabungan semuanya baik bersifat statis maupun dinamis yang membentuk satu rangkaian bangun yang saling terkait dimana masingmasing dihubungkan dengan jaringan lainnya.

\section{Aplikasi}

Suatu penerapan perangkat lunak (software) yang dikembangkan untuk melakukan tugas tertentu. Dalam pengembangannya, aplikasi dibedakan menjadi aplikasi desktop, aplikasi web dan aplikasi mobile. Aplikasi yang hanya dapat dijalankan di perangkat komputer disebut aplikasi desktop. Aplikasi web adalah Aplikasi yang dijalankan jika ada koneksi internet. Sedangkan aplikasi mobile adalah aplikasi yang dapat dijalankan di perangkat mobile. Suatu aplikasi dapat berjalan di berbagai perangkat dioperasikan oleh OS (Operating System) yang terdapat dalam perangkat tersebut.

Menurut [Firmansyah, 2017] Menjelaskan bahwa: Aplikasi adalah program siap pakai yang dapat digunakan untuk menjalankan perintah-perintah dari pengguna aplikasi tersebut dengan tujuan mendapatkan hasil yang lebih akurat sesuai dengan tujuan pembuatan aplikasi tersebut, aplikasi mempunyai arti yaitu pemecahan masalah yang menggunakan salah satu tehnik pemrosesan data aplikasi yang biasanya berpacu pada sebuah komputasi yang diinginkan atau diharapkan maupun pemrosesan data yang diharapkan.

\section{Sistem Informasi}

Sistem yang menyediakan informasi untuk manajemen pengambilan keputusan dan menjalankan operasional dari kombinasi orang-orang, teknologi informasi dan prosedur-prosedur yang terorganisasi yang bermaksud menata jaringan komunikasi yang penting, proses atau transaksi tertentu dan rutin membantu manajemen dan pemakai intern dan ekstern dan menyediakan dasar pengambilan keputusan yang tepat.

Menurut[Mania et al., 2016] "Sistem informasi adalah suatu sistem buatan manusia yang secara umum terdiri atas sekumpulan komponen berbasis komputer dan konvensional yang dibuat untuk menghimpun, menyimpan dan mengelola data serta menyediakan informasi keluaran kepada para pemakai".

\section{Pemendek URL (Short url)}

Menurut [Saputra and Astuti, 2018] "Nama domain atau Uniform Resource Locator (URL) adalah alamat unik di dunia internet yang digunakan untuk mengidentifikasi sebuah website, atau dengan kata lain domain name adalah alamat yang digunakan untuk menemukan sebuah website pada dunia internet".

Short url atau Shortener URL adalah teknik di mana URL dapat dibuat secara substansial lebih pendek dan masih mengarahkan ke halaman yang dituju. Dicapai dengan menggunakan HTTP Redirect pada nama domain yang singkat, yang menghubungkan ke halaman web yang memiliki URL panjang. Layanan ini dibuat agar memudahkan orang mengingat URL atau link. Banyak website yang menyediakan layanan Shorl URL atau shorter URL seperti adf.ly, shorte.st, bit.ly 


\section{Teknologi Website}

a. Website

Terdapat banyak informasi yang dibutuhkan dan juga dapat diakses secara cepat sehingga dalam pembuatan web diperlukan suatu website. Dalam dunia teknologi yang pesat diperlukan suatu jaringan yang mempermudah serta mempercepat penyampaian informasi secara luas, dan dapat dengan mudah oleh siapapun yang mendapatkan akses internet.

Menurut Hidayat dalam [Sundari, 2016] menjelaskan bahwa: website atau situs dapat diartikan sebagai kumpulan halaman-halaman yang digunakan untuk menampilkan informasi teks, gambar diam atau gerak, animasi, suara, dan atau gabungan dari semuanya, baik yang bersifat statis maupun dinamis yang membentuk suatu rangkaian bangunan yang saling terkait, yang masing-masing dihubungkan dengan jaringan-jaringan halaman.

b. HTML

Bahasa standar yang digunakan untuk menampilkan halaman web. Yang dapat dilakukan dengan HTML yaitu: mengatur tampilan dari halaman web dan isinya, membuat tabel dalam halaman web, mempublikasikan halaman web secara online, membuat form, menambahkan objek seperti audio, video, animasi, java aplet dalam halaman web, serta menampilkan area gambar (canvas) di browser.

Menurut Kadir dan Triwahyuni dalam[Priyanto and Siradjuddin, 2018] bahwa: HTML adalah bahasa markah yang digunakan untuk menyusun halaman web. Kodenya berupa kumpulan tag-tag, dengan setiap ditandai dengan $<$ dan diakhiri dengan $>$. Tag bisa mewakili elemen di halaman web, misalnya <img $>$ menyatakan elemen gambar serta pasangan $<$ a $>$ dan $</ a>$ menyatakan hyperlink..

c. PHP

Bahasa pemrograman yang digunakan secara luas untuk penanganan pembuatan dan pengembangan sebuah situs web dan bisa digunakan bersamaan dengan CSS dan HTML. PHP diciptakan oleh Dr. Leonardo Bernart pada tahun 1994. Pada awalnya PHP adalah singkatan dari "Personal Home Page Tools" selanjutnya diganti menjadi Forms Interpreter (FI). Sejak versi 3.0, nama bahasa ini diubah menjadi "PHP Hypertext Prepocessor" dengan singkatannya "PHP".

Menurut Nugroho dalam [Imaniawan and Elsa, 2017] "PHP merupakan bahasa standar yang digunakan dalam dunia website, PHP adalah bahasa program yang berbentuk skrip yang diletakkan di dalam server web".

Contoh PHP:

$<$ ?php

\{ echo "Nama Saya M. Robi Syahiri";

\}

?>

d. Database

Menurut Rosa dan Salahhudin dalam [Imaniawan and Elsa, 2017] "Sistem basis data adalah sistem terkomputerisasi yang tujuan utamanya adalah memelihara data yang sudah diolah atau informasi dan membuat informasi tersedia saat dibutuhkan".

Pada intinya basis data adalah media untuk menyimpan data agar dapat diakses dengan mudah dan cepat.

\section{METODE PENELITIAN}

Metode yang digunakan pada pengembangan perangkat lunak ini menggunakan model waterfall menurut Yurindra dalam [Yana Iqbal Maulana, 2017] yang terbagi menjadi tiga tahapan, yaitu: 


\section{Analisis Kebutuhan}

Tahapan ini sangat diperlukan dalam pengumpulan data dan pengumpulan informasi yang diperlukan. Informasi ini biasanya dapat diperoleh melalui wawancara, survei dan diskusi. Informasi tersebut dianalisis untuk mendapatkan dokumentasi kebutuhan pengguna untuk digunakan pada tahap selanjutnya.

\section{Perancangan Sistem dan Perangkat Lunak}

Proses perancangan sistem ini bertujuan untuk memberikan gambaran apa yang harusnya dikerjakan dan bagaimana tampilannya.

\section{Implementasi}

Pada tahap ini, perancangan perangkat lunak akan melakukan pemeriksaan terhadap sistem yang telah dibuat untuk direalisasikan sebagai serangkaian program.

\section{HASIL DAN PEMBAHASAN}

1. Analisa Kebutuhan

\section{a. Analisa Kebutuhan Pengguna}

Analisa kebutuhan pengguna website short url ini terbagi menjadi 3(tiga) bagian, yaitu user free, admin dan user premium. Berikut penjelasan dari masing-masing bagian.

1) Analisa Kebutuhan Admin

Pengolahan data yang dilakukan oleh seorang admin, yaitu untuk mengolah data-data yang ada di halaman admin seperti mengelola data web, data user, data beranda, tentang kami dan laporan short url.

2) Analisa Kebutuhan User free

Kebutuhan untuk user free yaitu dapat melakukan short url (memperpendek url) secara gratis dan maksimal untuk melakukan short url sebanyak 30 kali, untuk kebutuhan user free hasil dari short url akan acak (random).

3) Analisa Kebutuhan User premium

Kebutuhan untuk user premium yaitu dapat melakukan short url (memperpendek url) secara berbayar dan maksimal untuk melakukan short url sesuai dengan level yang beli, level tersebut yaitu :

a) jika membeli level Silver maka dapat melakukan short url sebanyak 100 kali dan hasil short url tersebut bisa sesuai dengan keinginan user.

b) jika membeli level Gold maka dapat melakukan short url sebanyak 200 kali dan hasil short url tersebut bisa sesuai dengan keinginan user.

c) jika membeli level Platinum maka dapat melakukan short url sebanyak 300 kali dan hasil short url tersebut bisa sesuai dengan keinginan user.

\section{b. Analisa Kebutuhan Sistem}

Analisa kebutuhan sistem mencakup hak akses, pengolahan data, dan keamanan sebagai berikut:

1) Hak akses

Sistem informasi short url dibuat untuk dapat diakses pengguna. Pengguna akan memperoleh menu yang sesuai dengan hak aksesnya. Hak akses tersebut yaitu:

a) Admin

1) Admin dapat melakukan login untuk masuk ke halaman admin dengan memasukan username dan password.

2) Admin bertanggungjawab untuk mengatur aktivitas website. Admin memiliki hak akses untuk menambahkan, mengubah, dan menghapus semua konten.

b) UserFree

1) User dapat melakukan pendaftaran untuk dapat melakukan short url. 
2) User dapat melihat informasi bagaimana cara melakukan short url.

3) User dapat melakukan short url sebanyak 30 kali.

c) User Premium

1) User dapat melakukan pendaftaran untuk dapat melakukan short url.

2) User dapat melihat informasi bagaimana cara melakukan short url.

3) User dapat melakukan short url secara unik atau sesuai keinginan user.

2. Pengolahan Data

Dalam pembuatan website ini membutuhkan beberapa data seperti :

a. Data fasilitas short url.

Berisi tentang informasi fasilitas short url yaitu ada fasilitas free, gold, silver dan platinum.

b. Data harga fasilitas short url.

Berisi tentang informasi harga fasilitas short url dari fasilitas fasilitas free, gold, silver dan platinum.

3. Keamanan

Website ini menyediakan keamanan untuk halaman admin yaitu halaman login, dengan memasukan username dan password. Untuk keamanan halaman user sama seperti halaman admin, yaitu login user, dengan memasukan username dan password. Selain itu tersedia layanan ubah akun yang didalamnya terdapat ubah data user serta ubah password dan lupa password yang disediakan agar halaman user lebih aman.

4. Kebutuhan Perangkat Keras (Hardware)

Kebutuhan perangkat keras (hardware) yang dibutuhkan dalam pembuatan website Sistem Informasi Short url Berbasis Web antara lain:

$\begin{array}{ll}\text { Procesor } & : \text { AMD E1-6010 with AMD Radeon R2 Graphics } \\ \text { RAM } & : \text { RAM 4GB } \\ \text { Harddisk } & : \text { Harddisk 500GB } \\ \text { Mouse } & : \text { Optical Mouse } \\ \text { Keyboard } & : \text { Standart Keyboard } \\ \text { Monitor } & : \text { Monitor dengan resolusi layar minimum 10 inch } \\ \text { Koneksi } & : \text { Koneksi internet dengan kecepatan minimal 2Mbps }\end{array}$

\section{Rancangan Perangkat Lunak}

Setelah proses analisa maka selanjutnya adalah proses perancangan. Perancangan berfungsi untuk pengembangan spesifikasi peragkat lunak, memberikan penjabaran bagaimana perangkat lunak yang dibangun dapat diimplementasikan. Perancangan perangkat lunak ini mencakup rancangan antar muka dan rancangan basis data. Berikut rancangan antar muka pada website Sistem Informasi Short url Berbasis Website sebagai berikut :

a. Rancangan halaman login admin

Rancangan halaman login admin dan halaman admin ini digunakan sebelum admin masuk kehalaman admin untuk mengelola website, yaitu dengan cara memasukan nama dan password admin. 


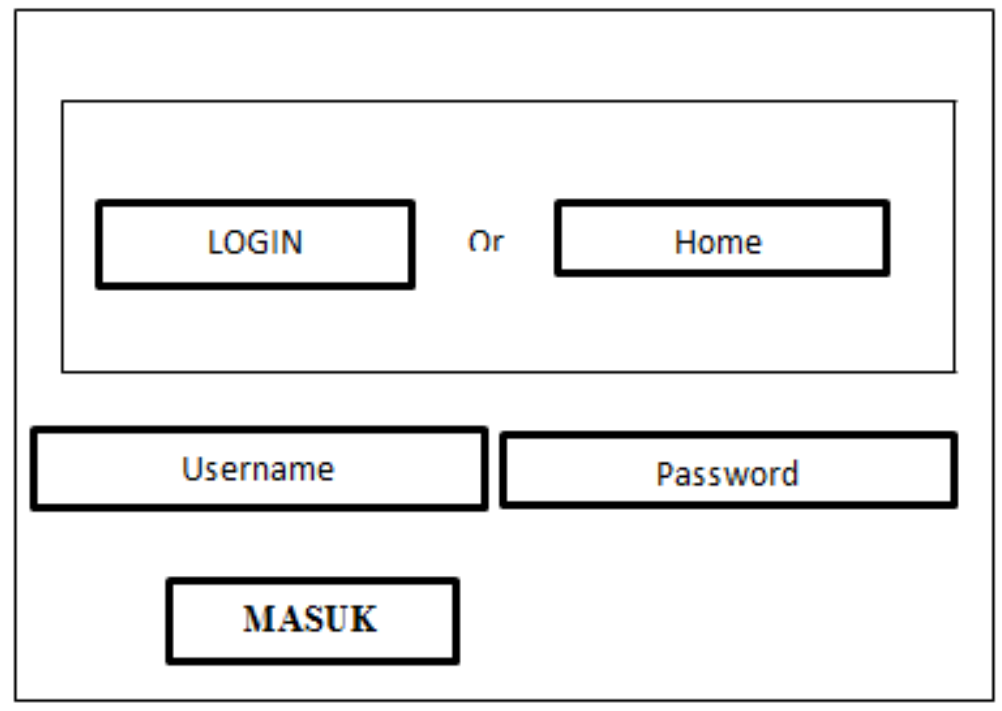

Gambar 1. Rancangan Halaman Login Admin

Halaman Login Admin terdiri dari :

1) Login

Tombol login untuk masuk ke halaman login.

2) Create an Account

Tombol Create an Account untuk membuat akun baru.

3) Username

Masukkan username berfungsi sebagai masukan untuk parameter otentifikasi username admin.

4) Password

Masukkan password berfungsi sebagai masukkan kata sandi untuk parameter otentifikasi password admin.

5) Tombol login

Tombol login digunakan untuk melanjutkan prosedur otentifikasi oleh pengguna setelah memasukan username dan password yang valid. Setelah berhasil login, admin akan dialihkan ke halaman utama index admin. Berikut rancangan halaman utama ruang admin

b. Rancangan halaman utama admin

Halaman ini adalah halaman utama administrator website. Pada halaman ini admin dapat mengelola semua data yang ada pada website.

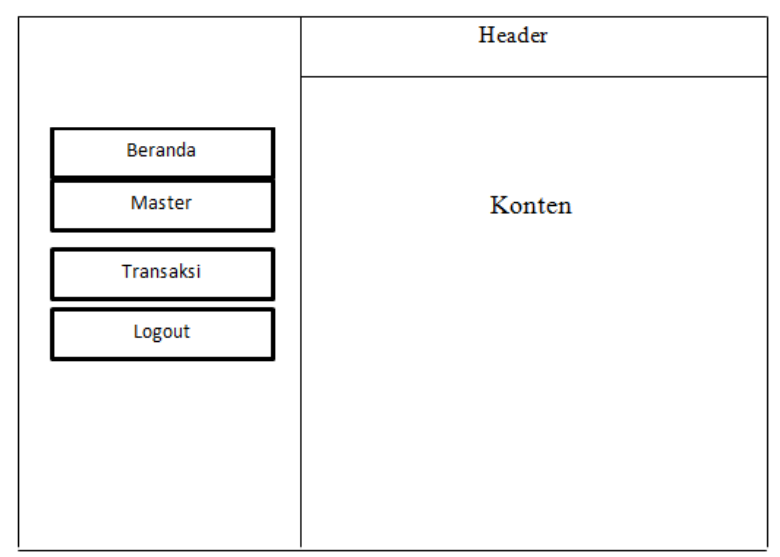

Gambar 2.Rancangan Halaman Utama Admin 
1) Header

Header digunakan untuk mengetahui halaman website, bahwa halaman ini adalah halaman admin.

2) Left Sidebar

Left Sidebar terdiri dari beberapa menu, yang masing-masing memiliki fasilitas dan fungsi yang berbeda. Berikut penjelasan dari masing- masing menu, yaitu:

a) Beranda

Menu ini akan menampilkan halaman beranda website.

b) Master

Menu ini akan menampilkan halaman data admin, data user dan data level.

i) Data Admin

Dalam tampilan data admin terdapat menu tambah, hapus dan edit, admin dapat melakukan tambah, hapus dan juga edit berikut tampilannya :

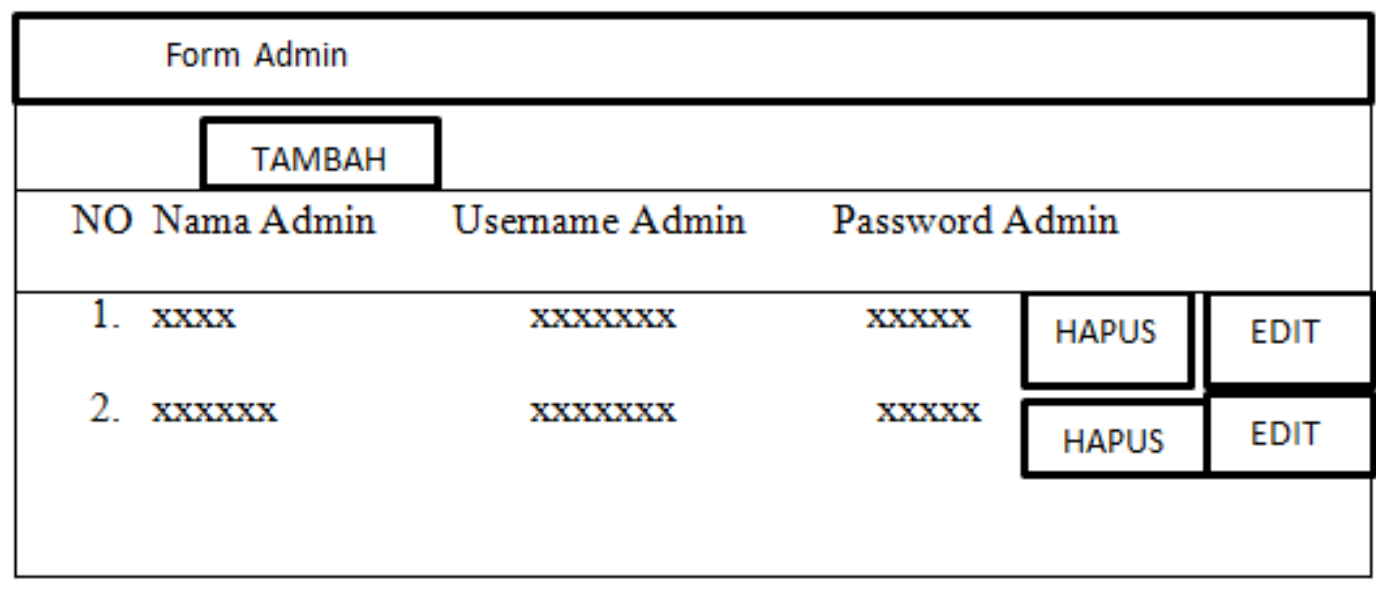

Gambar 3.Rancangan Halaman Data Admin

ii) Data User

Dalam tampilan data user terdapat menu tambah, hapus dan edit, admin dapat melakukan tambah, hapus dan juga edit berikut tampilannya :

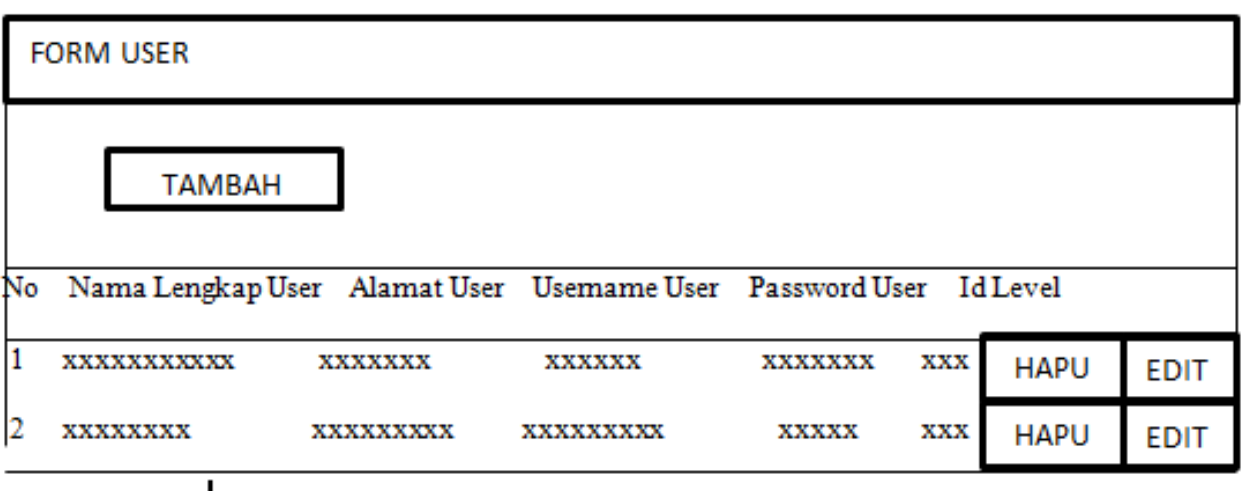

Gambar 4.Rancangan Halaman Data User

iii) Data Level

Dalam tampilan data user terdapat menu tambah, hapus dan edit, admin dapat melakukan tambah, hapus dan juga edit berikut tampilannya : 
IJSE - Indonesian Journal on Software Engineering, Vol.6, No. 1, Juni 2020, 94-106 pISSN: 2461-0690 I elSSN: 2714-9935

\begin{tabular}{|c|c|c|c|c|c|c|}
\hline \multicolumn{7}{|c|}{ FORM LEVEL } \\
\hline \multicolumn{7}{|c|}{ TAMBAH } \\
\hline No & Nama Level & FAsilitas Level & Banyak URL & Harga Level & & \\
\hline 1 & $\mathrm{xxxxxx}$ & $\operatorname{xxxxxxxx}$ & $\mathrm{xxx}$ & $\mathrm{xxxxxx}$ & HAPU & EDIT \\
\hline 2 & $\mathrm{xxxxx}$ & $\mathrm{xxxxxxxx}$ & $\mathrm{xxx}$ & $\mathrm{xxxxx}$ & HAPU & EDIT \\
\hline 3 & $\mathrm{xxxx}$ & $\mathrm{xxxxxxx}$ & $\mathrm{xxx}$ & $\mathrm{xxxxxx}$ & HAPU & EDIT \\
\hline 4 & $\mathrm{xxxxxxx}$ & $\mathrm{xxxxxxx}$ & $\mathrm{xxx}$ & $\mathrm{xxxxxx}$ & HAPU & EDIT \\
\hline
\end{tabular}

Gambar 5.Rancangan Halaman Data Level

c) Transaksi

Menu ini akan menampilkan halaman data user yang telah membuat akun premium atau upgrade dari level free ke premium dan menunggu aktivasi dari admin. i) Transaksi Data User

\section{FORM USER}

Gambar 6.Rancangan Halaman Transaksi Data User

c. Rancangan halaman utama user free

Halaman ini adalah halaman utama website user free. Pada halaman ini user dapat melakukan short url sebanyak 30 url.

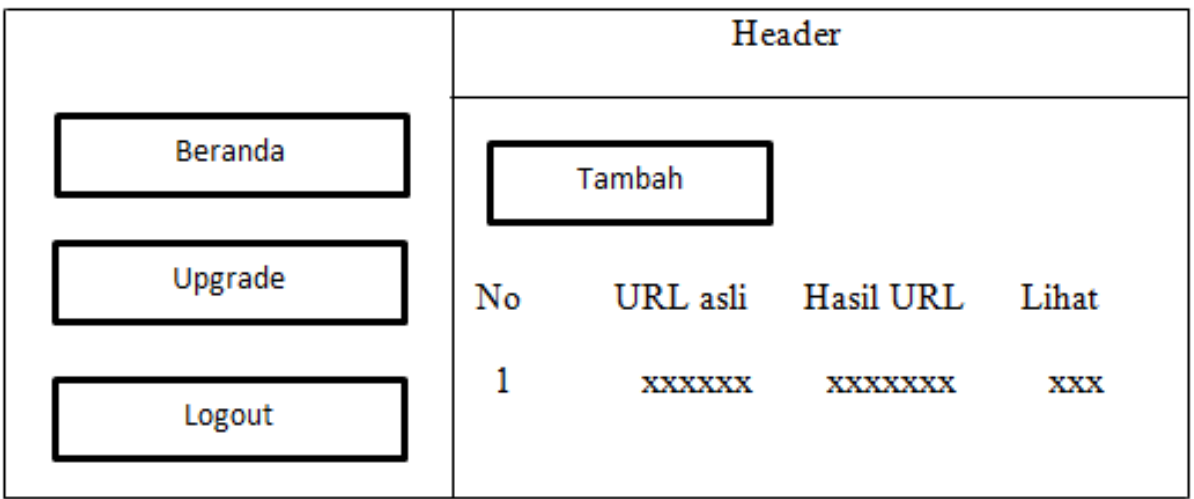

Gambar 7. Rancangan Halaman Utama User Free 
d. Rancangan halaman utama user premium

Halaman ini adalah halaman utama website user premium. Pada halaman ini user dapat melakukan short url dengan url free dan url unik.

\section{Entity Relationship Diagram (ERD)}

Perancangan basis data menghasilkan pemetaan tabel-tabel yang digambarkan dengan Entity Relationship Diagram (ERD). Berikut ini adalah Entity Relationship Diagram (ERD) untuk database website Sistem Informasi Short url Berbasis Web yaitu :

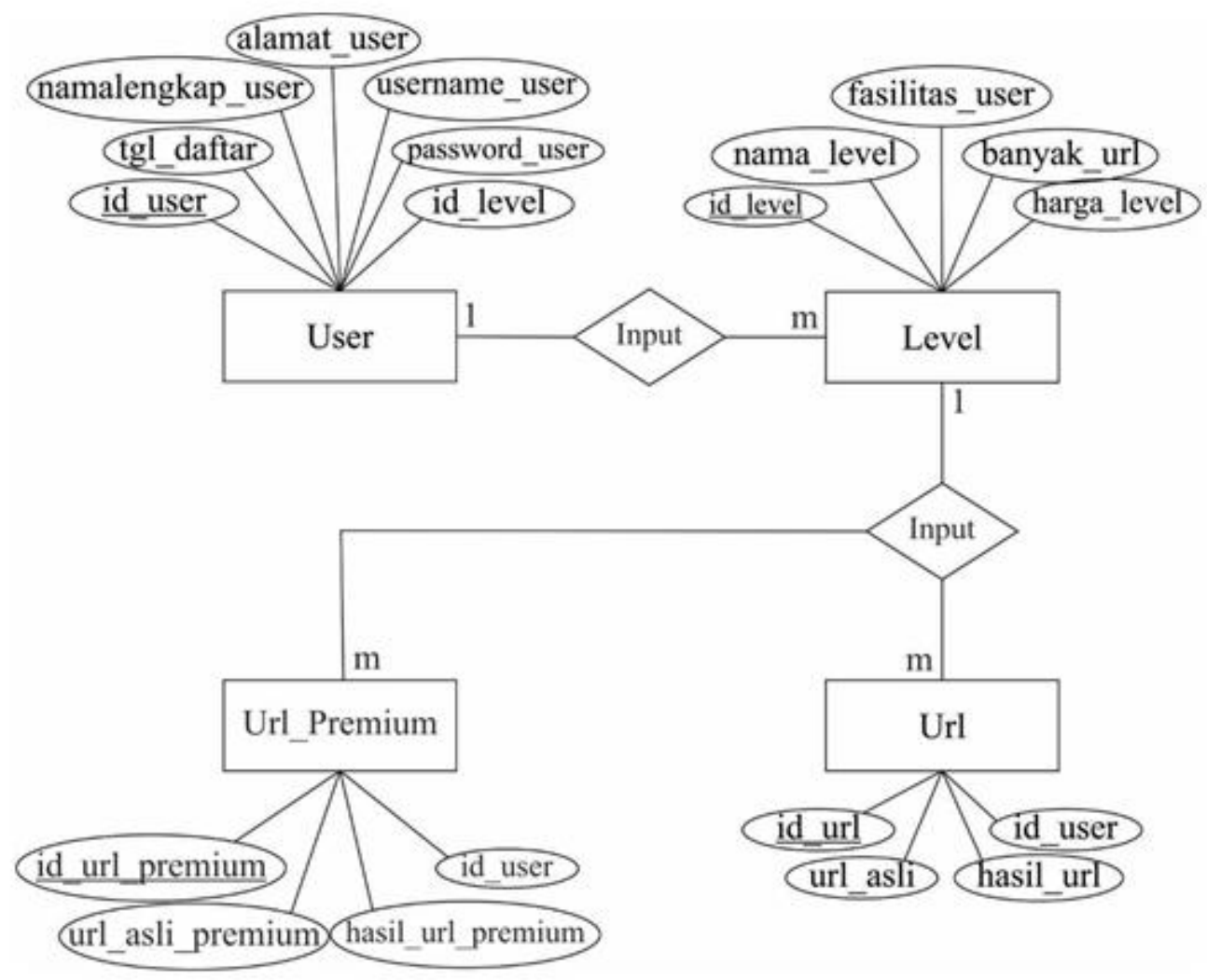

Gambar 8.Entity Relationship Diagram (ERD)

\section{Logical Record Structure (LRS)}

Logical Record Structure (LRS) merupakan konversi dari Entitiy Relationship Diagram (ERD) yang sebelumnya telah dibuat untuk memudahkan dalam mendefinisikan spesifikasi file. Logical Record Structure untuk basis data website Sistem Informasi Short url Berbasis Web yaitu : 


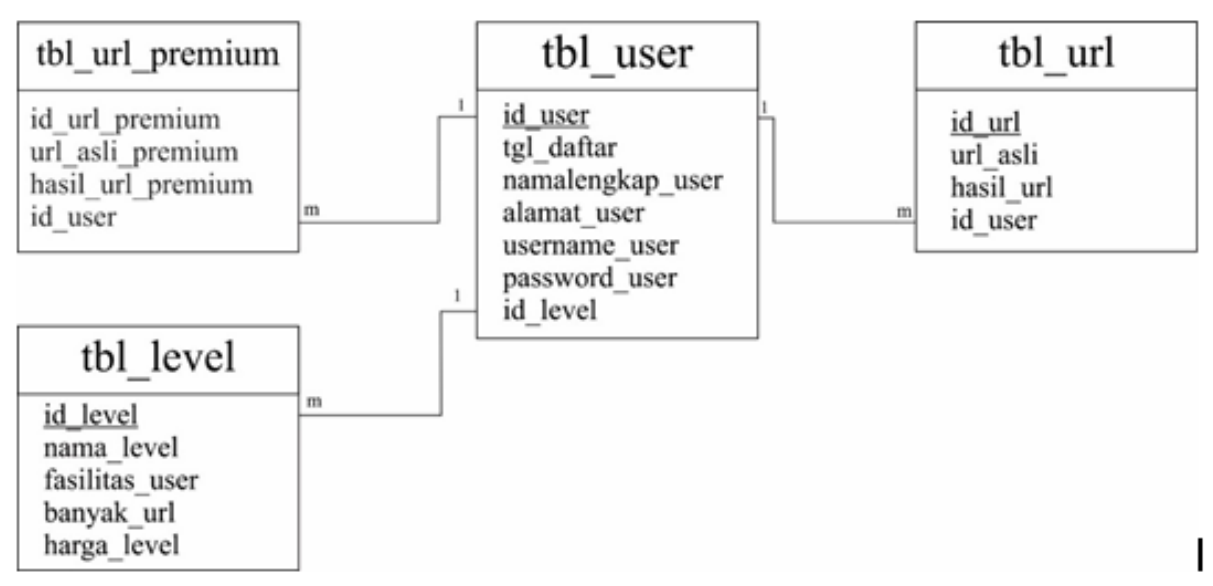

Gambar 9.Logical Record Structure (LRS)

\section{Implementasi}

a. Halaman Utama

\section{SI SOUP}

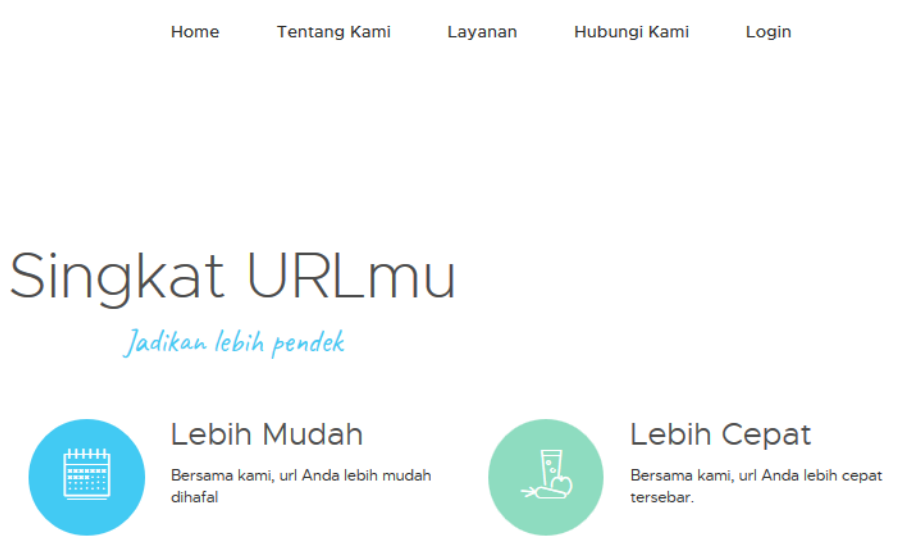

Gambar 10.Tampilan halaman utama

b. Implementasi Admin

1) Halaman Login

Tampilan awal ketika akan login

\section{Silakan Login}

Silakan login dengan username dan password Ande

$$
\text { Login }
$$

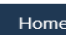

Username

Password

Gambar 11.Tampilan Login 
2) Halaman Utama Admin

Tampilan halaman utama admin

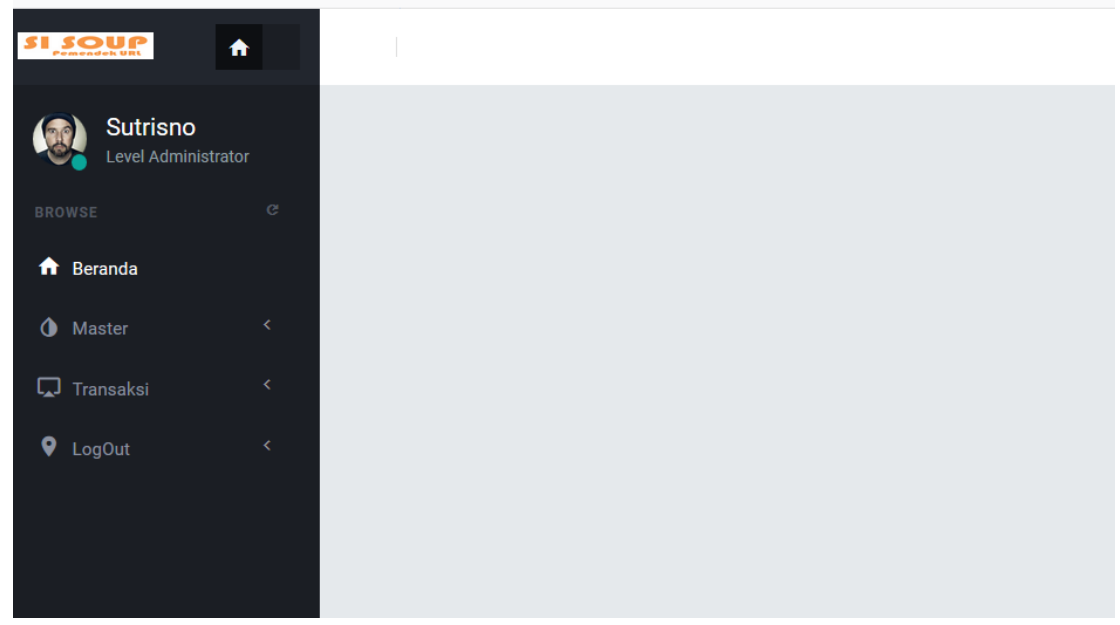

Gambar 12.Tampilan Utama Admin

3) Halaman Data Admin

Tampilan data admin

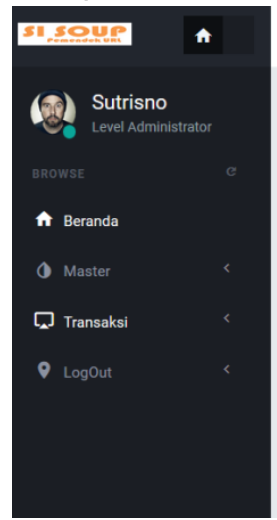

4) Halaman Data User

Gambar 13.Tampilan Data Admin

Tampilan data user
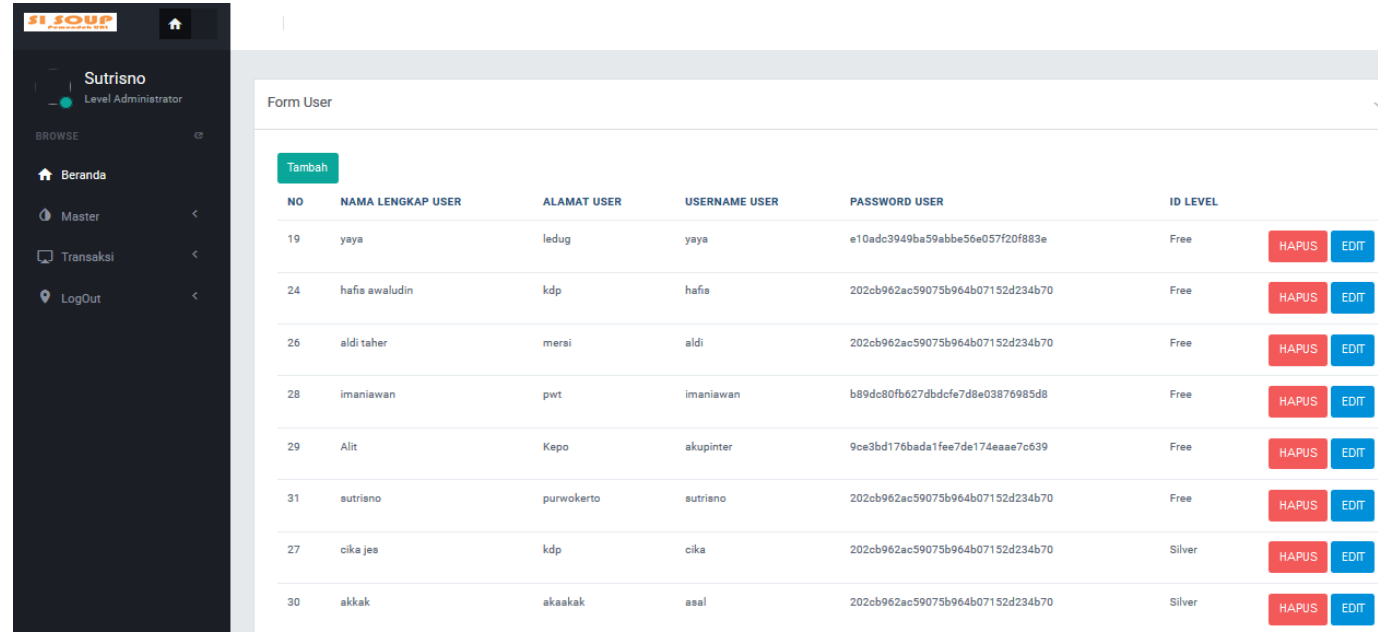

Gambar 14.Tampilan Data User 
5) Halaman Data Level

Tampilan data level
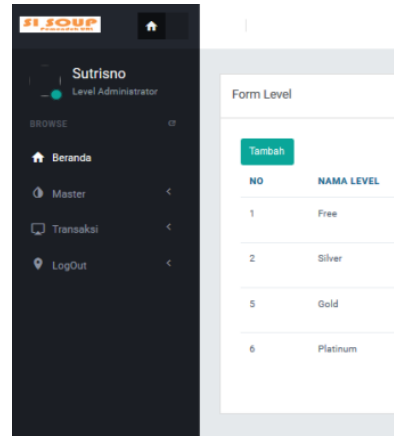

Gambar 15.Tampilan Data Level

c. Implementasi User

1) Halaman User Free

Tampilan user free

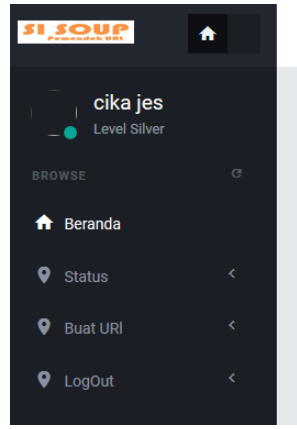

Eorm Urt

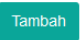

No URL ASL

\begin{tabular}{l} 
FASLITAS LVVE \\
URL Tilak Unik \\
\hline URL Unik \\
URL Unik \\
URL Unik
\end{tabular}
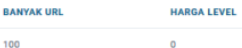

150000

20000

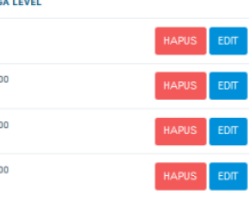


Eng. 2: 39-43.

Priyanto S, Siradjuddin HK. 2018. Sistem Informasi Pendaftaran Mahasiswa Baru Berbasis Web Pada Politeknik Sains \& Teknologi Wiratama Maluku Utara. Indones. J. Inf. Syst. 3.

Saputra A, Astuti DY. 2018. Analisis Pengaruh Struktur Html Terhadap Rangking Search Engine Result Page. J. Mantik Penusa 2: 34-67.

Sundari J. 2016. Sistem Informasi Pelayanan Puskesmas Berbasis Web. IJSE - Indones. J. Softw. Eng. 2: 44-49.

Yana Iqbal Maulana. 2017. Perancangan Sistem Informasi Aplikasi Penjualan Tekstil Secara Tunai. IJSE - Indones. J. Softw. Eng. 3: 92-97. 